\title{
La Poesía de González Prada
}

La poesía de González Prada no es complemento ornamental en su figura de pensador y combatiente, sino centro de su sisterna anímico, del cual parten y al cual confluyen todas las corrientes de su espíritu. De sus versos no podría decírse comó de la "hermosa cítara labrada". de Aquiles en la Ilíada: un mero deleite para amenizar los interregnos morosos del combate. Poesía y vida se entrelazan en este vaso transmitiéndose mutuamente sus poderes, por más que frente a algunas estrofas exquisitas y puras pensemos que éstas no pueden ser producto del gladiador político sino de un secreto cultivador de orquídeas. Compuso poemas de la más diversa índole dürante el trascurso de su existencia, con una aplicación de orfebre inclinado amorosamente sobre la tarea que sólo se explicar'gela Iuzidela Granvvocación, lejos del pasatiempo superficial del DILETANTTE. Escuchaba el llamado lírico y le daba cabida en su alma como a una corriente anegadora; a si vez en su poesía se encuentran todas las grandes preocupaciones objetivas, sus postulados sociales y humanitarios, su representación del mundo, de la naturaleza y de la vida, su angustia metafísica, su fe en la razón $y$ en la ciencia, su esperanza del porvenir $y$ hasta sus grandes enconos y sus odiosidades pequeñas. Su creación poética es así la síntesis del artista $\mathrm{y}$ del sagitario, en que puede analizarse la belleza más fina $Y$ noble, digna de las máśl altas inspiraciones de América, y el agonismo patético del hombre de ideas y de acción. Esta poesía es en nuestras letras una cima resplandeciente que se eleva sobre las convenciones de su tiempo, librándose de las influencias igualitarias por entonces en boga y abre el ciclo de nuestra lírica contemporánea. De él descienden, como por la diamantina ladera de los nevados la frescura fecundante, novedad y gracia, fuerza y sinceridad, depuración y gusto. Con este signo 
matinal lo reconocen los jóvenes de hoy y lo acata la crítica. Se ha publicado hace poco una antología de la POESIA CONTEMPORANEA DEL PERU que se inicia con sus versos (1). Los autores de esta selección. pese a naturales discrepancias, le acrediłan los méritos de "una nove. dosa modalidad que aparece entre nosotros para sorpresa y agitación provechosas, como extraña y precursora". Al de Prada siguen en ella los nombres de José María Eguren, César Vallejo, Marlín Adán, Emilio Adolı́ Westphalen, Xavier Abril, Enrique y Ricardo Peña, y Carlos Oquendo de Amat. La trayectoria de esia antología elude al modernismo propiamente dicho, representado por Chocano, y empalma a Prada con Eguren y Vallejo y la poesía de nuestro tiempo, dándole así a la obra de aquél una vigencia y una afinidad estélicas con lo más reciente de nuestro lirismo. Ya la ANTOLOGIA DE LA POESIA ESPAÑOLA E HISPANOAMERICANA de Federico de Onís, publicada en 1934, abría sus páginas con el poeta peruano, en el Pórtico de su T'RANSICION DEL ROMANTICISMO AL MODERNISMO, antes de Gutiérrez Nájera, Martí, Díaz Mirón, José Asunción Silva, Salvador Rueda y otros clásicos anunciadores del modernismo. "Su obra poética es limitada, pero significa un esfuerzo notable por la novedad dentro de la sencillez y la concentración, afirma Onís, una teacción contra el romanticismo desbordado y el verbalismo abundante y vacío que dominaba en América". Lo personal, trasparente $Y$ tefrenado del sentimiento la tersura parnasiana y clásica del lenguaje y el Uso de formas nuevas, son los caracteres que, para Onís, hacêñ dee Pradacinnebresagio des modernismo.

Prada había escrito versos desde su adolescencia, como resonan. cia de su aislamiento meditativo y de sus lecturas sistemáticas aunque libres de los clásicos españoles y de los autores franceses, ingleses y alemanes. La circunstancia de haber estudiado en el Colegio Inglés de Valparaíso y su tenaz empeño para el aprendizaje de las lenguas extranjeras más importantes, le franquearon la entrada al reino poco conocido en nuestro medio intelectual de las literaturas europeas modernas. Desde entonces traduce fielmente e imita a Goethe, Schiller, Heine y otros poetas germanos. Le son familiares Musset, Hugo, Baudelaire, Lecomte, Carducci, Byron, Shelley, así como los clásicos griegos y latinos y los españoles entre los cuales establece diferencias, distinguiendo entre todos ellos a Quevedo como el más grande escritor de la raza a quien

(1) Jorge Eielson - S. Salazar Bondy - Javier Sologuren: LA POESIA CONTEMPORANEA DEL PERU". I. Editorial Cultura Antártica. Lima, 1946. 
habría que buscar iguales, según sus propias palabras, "lejos del mundo español - en la Grecia de Pericles" (1). El amor a la poesía se acrecienta y fortalece en los ocho años de soledad que pasa en la hacienda de Mala, luego de abandonar los estudios universitarios. Allí, lejos de la contienda política que desdeña por su bajeza y barbarie, lejos del ambiente tradicional que lo comprime, en la paz eglógica del valle, en contacto con los labriegos sencillos y con el paisaje risueño, acendra su cultura durante largas jornadas de estudio. Escribe con abundancia, pero tambión destruye lo escrito por descontento orgulloso y castiga sin cesar aquello a que concede la existencia. Publica muy poco y siempre a insistencia de amigos y editores. En 1871 José Domingo Cortés imprime en Valparaíso el PARNASO PERUANO y en él apare. cen los versos que difunden y prestigian su nombre, ya reducido por la propia firma a Manuel G. Prada. Son composiciones de gusto clásico español, bajo la influencia de los Argensolas y de Fray Luis de León, con emoción religiosa y deísmo confeso. El gusto y la tendencia doctrinaria iban a variar mucho desde entonces. Las publicaciones se suceden de tarde en tarde en los periódicos y revistas de la época; pero el primer libro no aparece sino en 1901, bajo el nombre de MINUSCULAS y constituye parai él mismo una sorpresa. Su esposa Adriana de Verneuil y su hijo Alfredo, estampan la fina edición valiéndose de una prensa casera, en número de cien ejemplares fuera de comercio y se la ofrecen el 6 de enero, comofunhpresente de curmpleañosi En vida del poeta sóto se imprimen despues RRESBITERIANAS en 1909 y EXOTICAS en 1911. Después de su muerte, debido al anot filíal y" a la pericia bibliográfica de su hijo Alfredo, se publican TROZOS DE VIDA en 1933, GRAFITOS en 1937, LIBERTARIAS en 1938 y BALADAS en 1939. Por su parte, Luis Alberto Sánchez, con su devoción y autoridad sobre el tema, edita BALADAS PERUANAS en 1935 y ADORACION en 1947, como una contribución a los homenajes del actual Centenario. Alfredo, desaparecido en 1943, dejó anunciado un último libro, DISJECTA MEM$\mathrm{BRA}_{t}$, con todas las poesías que aun quedaban sin reunir en volumen, esparcidas en diferentes publicaciones o inéditas.

Es difícil fijar el arden cronológico verdadero de los ibbros poéticos de Prada si prescindimos de la fecha de las ediciones. Con excepción de MINUSCULAS y EXOTICAS que constituyen momentos de una evolución estética y de TROZOS DE VIDA que forma el mensaje lírico de los últimos días del poeta, los demás juntan composiciones de muy dis-

(1) Gratito No 67 de GRAFITOS. 
tintas épocas, reunidas por la afinidad de los temas. Sin embargo, precisaré su contenido por el orden en que se entregan al público con objeto de no detenerme en problemas de aclaración compleja. Le da. ré amplitud al anćlisis de T'ROZOS DE VIDA por su carácter de síntesis geométrica, en que se cristaliza toda la obra anterior y se percibe nítidamente la sensibilidad y el ideario del poeta. MINUSCULAS (ediciones de 1901، 1909, 1928 y 1947) comprende desde algunas poesías insertas en el PARNASO PERUANO de Cortés hasta otras próximas a la fecha de la primera edición. Es el resultado de un severo escogimiento de gusto exquisito que logra para las letras peruanas un libro fundamental y eterno. Se encuentran aquí las realizaciones más primorosas, delicadas y diáfanas, de las cuales va a ser EXOTICAS una culminación cenital y TROZOS DE VIDA un poniente sabio, pomposo y rnelancólico. PRESBITERIANAS (ediciones de 1909 y 1928) es un pequeño tomo de epigramas y sátiras anticlericales que pertenecen más a la aljaba del agresor político-social, obsesivo y convulso, que a su obra poética, aunque muchos de ellos están morosamente elaborados. El cinismo y la obscenidad rabelesianos carecen aquí de la amplitud para comprender a la sociedad entera en la crítica de sus abusos y deformaciones y del cromático realismo que enciende las descripciones del cura de Meudón. A fuerza de ser el único culpable de los más afrentosos vicios y de constitưin una àstracción désprendida de la masa social, el clero aparece como un arquetipo grotesco, irreal y absurdo, creado a propósito para recibir los rayos de su tonante indignación. EXOTICAS prosigue la línea de MINUSCULAS, superando su ardimiento de gracia y su potencia renovadora. Corresponde a la época de permanencia del poeta en París y por lo tanto de asimilación entusiasta y fervorosa de horizontes ignorados. Añade a MINUSCULAS formas y motivos flamantes, movilidad y energía creadora. TROZOS DE VIDA abarca la producción de los últimos sels meses de la vida del autor, emocionante CORONA OPERIS realizada en un solo molde estrófico: octavillas asonantadas al modo del romance, simples y sordas, como hundidas en la cogitación final del pensador y del artista. Se encuentran aquí, severamente cifradas en 153 de estas octavillas, las ideas que han vagado con fragosa agitación por toda la obra y que llegan como a posarse en sueño tranquilo bajo un fanal limitado y traslúcido. El dolor cósmico que se hunde en la amargura de contemplar el sufrimiento inexorable de todos los seres y que parece centrarse en el hombre y en sí mismo, tiene su expresión en las octavillas $28,29,41,42,45,51,56,57$. Ante el sucederse ciego del infortunio y de la muerte encuentra en la mon- 
taña cubierta de hielo y en la mujer estéril los símbolos perfectos de su actitud filosófica:

Montaña excelsa, no sueñes

el verdor primaveral:

deja al llano las fruiciones

de la vil fecundidad.

Arropada en nieve elerna, como un armiño imperial, sigue a la mujer estéril, ten su noble majestad.

Ya en el primer poema de MINUSCULAS la mube que cruza el firmamento sonríe ante la apariencia bonancible del paisaje,

mas al mirar asolación y espanto.

odios y guerras, muerles y dolores,

lanza un gemido y se deshace en llanto.

La tragedia de la agnosis que atenacea su alma y que la ennoblece con la duda metafísica por sobre sus estridentes afirmaciones de ateísmo se manifiesta en las logtavillas $30,31,32,33,19,50,98:$

Ni verdades "las verdadesinelli Converso"

ni mentiras las mentiras.

Para rumbo del cerebro

¿Dónde hallar la estrella fija?

Todo sombras $y$ apariencias;

todo vaga, todo gira,

en la caótica noche

de una cueva sin salida.

En EXOTICAS (1) la Naturaleza es la conductora "de la infancia a la vejez, de la vejez al GRAN ABISMO", y en medio de la chocarrería de los GRAFITOS afirma esta sentencia qrave:

...Pues los hombres hoy morimos como los hombres de ayer: 
con el miedo en las entrañas

y con la duda en la sien,

yendo a buscar en la tumba

un oscuro PUEDE SER.

\section{(GRAFITO 41)}

Sentencia, por lo demás, ya dicha en forma de aguda interrogación en el RONDEL de Minúsculas:

...¿Por qué sin tregua ni quietud luchamos?

¿Qué vemos al final de la jornada?

La eterna vida o la infecunda nada?

¿A dónde vamos?

El desengaño supreme de la vida por su fugacidad, "vanidad de vanidades y todo vanidad", en extraña proximidad al Eclesiastés y al Kempis, lo trasunta la octavilla 48:

¿Qué sabbat de formas vanasl

¡Qué girar vertiginoso

de jlusorias apariencias!

Todo miente, engaria todo.

¡Cuán distinto el unverso Letras

de lo qūendicenulosiojosli.Converso»

Desengaño que tiene antecedentes copiosos en MINUSCULAS:

...Subsiste el duelo, pasa la alegría:

dura un siglo el ciprés, la rosa vive un día.

(Rondel)

...Aves de paso que en flotante hilera,

recorren el azul del firmamento,

exhalan en los aires un lamento,

$y$ se disipan en veloz carrera,

son el amor, la gloria $y$ el contento...

(Rondel)

Los bienes y las glorias de la vida

o nunca vienen o nos llegan tarde. 
Lucen de cerca, pasan de corrida, los bienes y las gloriasi de la vida...

(Triolet)

Humo y nada el soplo del ser: mueren hombre, pájaro y flor, corre a mar de olvido el amor, huye a breve tumba el placer...

\section{(Vivir y Morir)}

Esta desilusión del mundo hace más cara la soledad tajante y senorial que palpita en las octavillas $66,78,81,89,123$ :

- ...Lejos yo de las ciudades

abstraído voy y solo..

Misantropía que repite, después de cincuenta años y tras otras rejteraciones, la del verso juvenil del PARNASO PERUANO:

En el mar proceloso de la vida eres mi puerto, soledad querida...

pero el desencanto de las cosas y de los hombres no se reduce a buscar el relugio de la soledad dofide su "apma vibia" y se difunde" sino que lo impulsa hacia la evasión por el tiempo hacia el porvenir:

...Que esta raza no es mi raza,

que este siglo no es mi siglo:

yo debí nacer mañana.

(67)

A la evasión por el espacio hacia distantes mirajes;

.. Q Quién a la nave subiera

$y$ en la nave se alejara!...

(68)

A Ia evasión sideral hacia los soles y las estrellas que chispean en el firmamento: 
Si en las miriadas de mundos, existe un mundo viril, si hay un astro de rebeldes, oh muerte, llévame alli. ma:

Y a la evasión por la muerte, afrontando la solución del gran enig-

Posadero, da posada

al cansado peregrino.

Bajo dosel de cipreses,

dame un lecho duro y frío:

porque el sueño que me agobia

no es un sueño fugitivo:

es un sueño interminable.

es un sueño de granito.

(62)

Esta SUITE de la evasión que se perfila en TROZOS DE VIDA tiene sus antecedentes simétricos en el resto de la obra, particularmente la evasión hacia los astios:ioteca de Letras

\section{En mar" deriz milcorazón navedárso" por siderales voces atraído...}

(Pantum sin Rima. MINUSCULAS)

Pero no todo es sombrío pesimismo y execración en el postrer sistema lírico de Prada. El universo se ilumina a veces de ensueño amable. de exultación cordial, de fe en algo invisible aunque no sea la concepción divina del cristianismo. Siente la necesidad de afirmarse en determinadas creencias. Podríamos decir que éstas son cuatro esenciales que renuevan radicalmente su actutid $\mathrm{y}$ le infunden aliento poderoso $\mathrm{y}$ férvido: el amor; la belleza; el progreso humano basado en la razón y en la ciencia; y la misteriosa armonía y unidad del Cosmos en que palpita una presencia indefinida pero insistente:

...Venid, poned el oído

y escuchad el corazón: 
en él su canto divino está cantando el amor .

Confesión que concierta, entre otros precedentes, con el Laude de EXOTICAS:

...Celebremos al amor como rey y gran señor. A torrentes brota dél toda luz y toda miel. en sus labios toda hiel da dulcísimo sabor...

La hermosura de los campos y los cielos, la gravedad de las montanas, la delicadeza de las flores le producen una fascinación estática:

¡Quién amaral 1 Quién viviera

en dulcísimas congojas

y muriera respirando

la fragancia de una rosal

\section{(107)

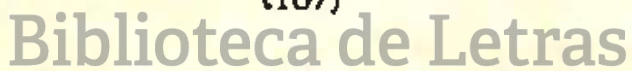 \\ Fascinación que está ya compendiada en MINUSCULAS:}

De cuantos bienes atesora el mundo, el bien supremo, el de mayor grandeza, emana de tus formas, oh Bellezal...

\section{(Balata)}

El optimismo sucede al desconsuelo como un aura refrescante cuando luego de contemplar la organización social del presente piensa en el futuro:

Paso a paso, mas de frente siguen su marcina los hombres, despojándose del bruto, alejándose del bosque... 
Esta confianza adquiere caracteres proféticos, casi litúrgicos, en LIBERTARIAS:

...Quiero anunciar el venidero día a los cobardes que en la noche duermen, quiero en las almas derramar un germen de amor, de libertad, de rebeldía.

(Lo que yo Quiero)

... jQue en todos los campos florezcan los mirtos!

¿Que en todas las almas germine la dicha!...

(El Himno Futuro)

La intuición de la fraternidad cósmica que alcanza desde los se. res más pequeños $y$ desdeñados hasta los mundos astrales donde presiente "un oculto más allá", lo empapa de emoción panteísta, vagamente religiosa:

Invisibles hilos de oro

van del gusano a la estrella...

〈91)

Todo es uno en la divina identidad de las cosas.... Converso"

(95)

Emoción que viene desde el fondo de la obra:

Oigo el rumor de lunas y de soles, escucho el palpitar del universo...

(Rondel-Romance. MINUSCULAS)

Las cosas se unen a las cosas, los seres se confunden con losi seres...

(La Gran Familia. EXOTICAS)

Me he detenido a precisar el ideario de TROZOS DE VIDA por su carácter de SUMMA POETICA que caracteriza al volumen, aunque no supera la belleza de la obra de juventud. Esta se contiene en MINUSCULAS y EXOTICAS y, en parte, en los dos tomos de BALADA.S. Los 
libros póstumos, en general, tienen el defecto de haber recogido indiscriminadamente los poemas, llevados los editores de un criterio documental, útil para la crítica, pero en menor grado para la estética literaría. Muchos de esos poemas son primeros esbozos condenados u olvidados por el autor, en gran cantidad incompletos, a menudo fallidos, esqueletos levantados del osario de lo pueril o lo pedrestre a que tienen derecho todos los artistas.

El autor dispuso un solo tomo de B.ALADAS, pero me parece certera la separación del grupo que incide en temas nacionales con el nombre de BALADAS PERUANAS (edición de 1935). Son éstas, como las de tema universal, composiciones épico-líricas de corte sobrio y elegante, inspiradas en las leyendas y mitos de la raza aborigen, en los años de la violencia conquistadora $y$ en la realidad trágica de los indios de hoy. La lozanía del mundo y de los hombres recién aparecidos, captada a menudo de los relatos cosmogónicos de Garcilaso, el cuadro de sangre y de codicia instaurado por Pizarro, la protesta frente a la iniquidad cuatricentenaria, círculan por el verso:

..."- ¡Piedad, piedad, Viracocha!"

clama el indio de rodillas:

mas el blanco ignora quejas

y el sangriento azote vibra.

\section{Biblici Chasquir Ietras}

LAS BALADAS PERUANAS inauguran en nuestra poesía el tema vernáculo que los romáticos habían tratado sólo ocasionalmente o como recurso decorativo y que la inspiración de Chocano va a elevar a calidad estética y jubileo sensorial, sin calar hondo en la entraña dolorosa y acezante. "Con Prada se inicia la campaña indigenista nítida. Con él se ahondó el sentido del canto peruano" señala Luis Alberto Sánchez al revelarnos estas páginas. La colección encierra un material heterogéneo desde el punto de vista artístico, pero priman un aire delicado que nimba la narración y el innegable calor del rescoldo telúrico.

GRAFITOS (edición de 1937) contiene la producción epigramática y satírica de Prada, la colección no de sus grandes venablos sino de sus saetas breves y ágiles, para los golpes menores, aunque a veces no menos desgarrantes. Les dió el nombre de GRAFITOS explica Alfredo González Prada "queriendo tal vez significar que a la manera de los GRAFFITI clásicos, nacieron estos pequeños poemas al capricho de la ocurrencia y con la espontaneidad con que las inscripciones, dibujos, ca- 
ricaturas y garabatos aparecen trazados sobre los muros de los edificios antiguos". Están compuestos en versos de arte menor, formando pareados o estrofas de cualro o cinco versos, aunque hay algunos más amplios. Los temas son literarios, políticos, sociales, amorosos, religiosos, sobre viajes y sobre motivos puramente epigramáticos, centelleo de paradojas y sarcasmo, trazos rápidos y enfáticos, risa que no alcanza a desleir el rictus de la cólera.

LIBERTARIAS (edición de 1938) reune los versos civiles inspirados en el ansia frenética de emancipación que condensa la página liminar con el símbolo de la nave sin bandera, ni brújula, ni piloto, ni timón $y$ que

navegue feliz o perezca, se arroja a los mares,

se arroja por sirtes y yórtices,

sin Juna, luceros ni sol.

Han sido añadidas las composiciones de otros libros que guardau relación con el asunto común. Algunos poemas tienen aliento poético vigoroso como "El Arbol" y "El Ultimo Grito", pero por lo general sufren la chatura de la imposicjón didáctica, el rigorismo de una doctrina demasiado malemática. En GRÄFTOS y en LIBERTARIASS la poesía es huésped de la dialéctica y está comprimida dentro de un pupilaje rectilíneo en forma que a menudo se reduce o se desvanece por completo.

En general Prada es un altísimo poeta cuando hace poesía pura o cuando lleva hasta la esfera poética sus inquietudes vitales, aunque éstas sean doctrinarias; pero lo es mucho menos cuando teniendo por mira inmediata la propaganda o la polémica en torno a sus principios ideológicos, moviliza la poesía al servicio de estos fines estéticamente secundarios. Entonces cae en el prosaísmo, la frialdad o el mal gusto, lo que se ha agravado con las publicaciones no autorizadas por él. Pero en esa primera actitud, la propiamente lírica, tiene un caudal de aciertos que hacen innecesarias para una valoración artística, las de. más partes de su obra. Esta puede quedar confinada así a MINUSCULAS y EXOTICAS, a la mayor parte de TROZOS DE VIDA, BALADAS PERUANAS y BALADAS y a una extracción severa de GRAFITOS y LIBERTARIAS. ADORACION es un libro romántico, de confidencia a la mujer amada, con propósito muy personal e íntimo, en el cual no hay versos que merezcan la antología, aunque pueden ser útiles para un juicio integral del poeta. 
I.as BALADAS, de carácter universal, constituyen el tronco inspirador de donde se derivaron las de asunto peruano. El poeta gustó desde la juventud de la balada que es un mensaje breve, fino y vagoroso del reino de la imaginación. Alli los hechos referidos son cortos, las emociones sutiles y melancólicas, Jo sobrenatural pone un soplo de misterio $y$ deliciosa incertidumbre, elementos todos que coincidian con su manera de sentir la belleza. Tradujo baladas de los grandes poetas alemanes y franceses y compuso muchas oríginales, con sujeción a las reglas clásicas del género y con inspiración selecta y primorosa. Sobresalen "El Pescador Loco" por su expresión lírica de la fatalidad, "Escena Feudal" por su dramalismo bárbaro, "El Rey Perjuro" por su contraste romántico, "El Islamismo" por su colorido oriental y "El Parricida", "Mancha Indeleble" y "El Rey de los Elfos", sobre un molivo de Goethe, por el hálito de lo inexorable y divino.

Entre sus cualidades positivas está su virtuosismo métrico y su fuerza creadora y transformadora de módulos poéticos. Sacerdole grave de la euritmia habita "el albo y harmonioso edificio de su verso clásico - con palabras de Manuel Beltroy - en cuya arquilectura el mármol pentelio se anima y cobra animación vital". Es gran conocedor teórico de la ciencia del verso como lo demuestran su erudito ensayo sobre "El Verso de Nueve Silabas" y sus "Notas" y escolios en EXO. TICAS. Tiene desdén por la rima que considera un "pueril cascabel" Y la fué abandonando l paulatinamented pero, fuzqua siempre indispensa. ble el ritmo de acuerdo con su ideal helénico de la nitidez y el equili. brio. En uno de sus Grafitos expresa este concepto:
Excusemos al poeta cien enormes barbarismos, pero no le perdonemos un pecado contra el ritmo

Concepto que reitera tratándose de Campoamor:
Excelentes cosas dices con deficienclas de ritmos: haces pensar en Apolo cabalgando en un pollino. 
El cabalgó siempre en un corcel de saltos musicales, exquisitamer te armoniosos y numéricos, e inventó nuevas combinaciones acentuales como sus endecasilabos con hemistiquio esdrújulo y $\sin$ acentos en cuarta, sexta $y$ octava; sus imitaciones ritmicas de la estrofa alcaica, del metro sotádico y del dístico elegíaco; y. sobre todo, con sus "polirritmos sin rima". Para Carlos García-Prada, el polirritmo sin rima es su creación poemática más interesante y sorprendente por su "honda, varia y refinada armonía" y la que prepara el advenimiento del verso libre en castellano. Muchas de estas innovaciones rítmicas fueron después asimiladas por el moclernismo y ejercidas con amplitud en América y España.

Este mismo aliento transmutador anima sus estrofas. Hubiese sido imposible a tan gran descontento resignarse con los dechados inmenoriales, estrechos y pobres que hasta entonces se reputaban como únicos en español. En consecuencia, trajo del francés, del inglés y del italiano, nuevas estrofas para adaptarlas a nuestro idioma, e inventó por su cuenta otras. Las principales son las siguientes:

El RONDEL, formado por quince endecasílabos que se dividen en tres partes: de cinco, de cuatro y de seis versos, respectivamente. Por lo general los versos finales de la segunda y tercera parte son un bordoncillo de siete sílabas. La rima cambia de una composición a otra, pero en general juega con no más de seis variantes que se reiteran. El RONDEL, como el TRIOLET y P VILLANELA forman parte de una misma familia lírica ry aprozienercideelai foestäenoyadoresca francesa de la Edad Media.

El TRIOLET, compuesto por ocho versos que pueden ser de ocho a doce sílabas con sólo dos rímas que se combinan generalmente 1-2-1 -1-1-2-1-2. El primer verso se repite en forma de RITORNELLO al medio $y$ al fin del poema.

La VILLANELA consta de un número indefinido de tercetos octosílabos con rima 1-2-1, repetida idéntica en todas las estancias y que termina con un cuarteto de las mismas rimas distribuidas 1-2-1-1.

La ESPENSERINA junta ocho versos de once sílabas a uno de trece, con rima 1-2-1-2-2-2-3-2-3-3. La espenserina fué inventada por el poeta inglés Edmund Spenser del siglo XVI. Prada disminuyó el último verso en una sílaba, pues en inglés tiene catorce.

El RISPETTO reune un serventesio $y$ tres dísticos endecasílabos con la rima consiguiente: $1-2-1-2 \ldots 3-3 . .4-4 \ldots 5-5$.

La BALATA que vino de antiguo al español procedente del italiano, se había olvidado y Prada la introdujo nuevamente, estudianda los mo- 
delos originarios. Consiste en una combinación de dos estancias de tres versos, al principio y al fin, con una de cuatro al medio, generalmente endecasílabos. Uno de los versos se repite hasta tres veces como bordoncillo.

El ESTORNELO, procedente también del italiano, consta, por lo ge neral, de un verso heptasílabo y dos endecasílabos con rima 1-2-1.

El PANTUM, de origen malayo, usado por Baudelaire, se compone de cuarto cuartetas de versos endecasílabos que riman 1-2-1... 3-4-3-4 .... 5-6-5-6 .... 6-1-6-1.

El LAUDE, invención de Prada, teniendo presente probablemente las LAUDAS italianas, comprende diez versos octosílabos divididos en tres partes: la primera de dos y la segunda y tercera de cuatro, con ríma: $1-1, \ldots .2-2-2-1 \ldots . .3-3-3-1$.

El cuarteto persa, de adaptación oriental, se forma de versos de diferente número de sílabas, ya iguales en su metro, ya de metro diferente pero combinado, con rima 1-1-2-1.

La GACELA, invención de Prada, consta de diez o doce versos endecasílabos o dodecasílabos. Los dos primeros riman entre sí y esta misma rima se repite en los versos hasta el décimo. Los demás versos carecen de rima. Esquema: 1-1-0-1-0-1-0-1-0-1.

El POLIRRITMO SIN RIMA, sin poderle llamar estrofa, constituye no obstante un todo funcional $\mathrm{y}$ complejo, absolutamente armónico. Es una sucesión de versosi hindependientes formadosapor combinaciones muy sabias y equilibradas de variados elementos rítmicos.

Poeta de calidades mútiples $Y$ contradictorias, tiene por sobre to das ellas la excelencia de este fermento renovador de la poesía hispano-americana. Su enjuiciamiento debe por eso situarlo en relación con lo que había en el momento en que apareció y con lo que vino como consecuencia de su enseñanza. Intrínsecamente es un romántico y un parnasiano. Romántico por la congoja suprema que lo agobia, aquel tenebroso pesimismo ante el espectáculo del dolor cósmico y que lo acerca a Leopardi; por la redención con que lo transfigura el amor; por la frenética esperanza en la Razón, la Ciencia, la Libertad; en general, por su "pathos" desgarrado y trémulo. Parnasiano por la continencia discreta del verbo en tiempos de grandilocuencia retórica, por la belle za plástica del verso marmóreamente esculpido a la manera de Banvilie y de Lecomte, por el amor al clasicismo griego cuyos dioses y pámpónos añora. Su sentido reformador no es tampoco incompatible con 
su formación clásica española $y$, en cierta forma, con su gusto por lo castizo más vigoroso y original. Es un individualista señorialmente retraído en la soledad, pero en ella escucha el tormento del hombre esclavizado y sale para grilarle su solidaridad, con vehemencia profética. Le entusiasma el mundo objetivo con su verosimilitud y su lógica pero se escapa a las esferas del imaginismo puro donde se estremecen seres enigmáticos entre luces superrealistas. Es oficialmente aleo y no abandona su máscara de convicción escéptica; pero lo desborda lo que García Prada llama su "religiosidàd ahogada", su anhelo del MAS ALIA y su fe en INVISIBLES HILOS DE ORO. Es estoico como un eremita del desierto que sólo se alimenta de raíces salvajes, hasta que lo llama la fiesta de la vida y entonces nos convoca a gozar las exquisitas ofrendas, de inmediato, en la mañana, porque en la tarde puede ser ya imposible. Ejerce la admonición candente tanio como la confidencia melodiosa. Es en fin, según Ventura García Calderón, el menos peruano de los escritores por la pertinacia de su rebeldía en un medio donde los años docilizan a los hombres, por su inquietud grave y su cólera donde todo es fiesta $y^{*}$ sonrisa; perd también podríamos decir, para complelar este cuadro de antinomias reducibles dentro de la fuerza conjugante de toda gran personalidad, que es el más peruano de los poelas si lo enraizamos no en la tradición cortesana del virreynato sino en la esencia aborigen que captó a pesar de su raza europea: tiene el sentido cósmico que viene dellpais profundo, planetatio;ala austeridad y la melancolía que son flöresgde nuestra biedranveels ganto suave y afiligranado como un arabesco de Chavín o de Paracas. Peruano, en suma, hasta en la invectiva contra lo suyo si interpretamos su explicación del amor:

Mas no te extrañes si en mi enojo

te maldijera yo a tí:

en la lengua del amante

maldecir es bendecir.

(TROZOS DE VIDA. 141).

Lima, enero de 1948.

IOSE JIMENEZ BORJA. 